\title{
Consumo, digestibilidade e excreção de uréia e derivados de purinas em novilhas de diferentes pesos ${ }^{1}$
}

\author{
Mario Luiz Chizzotti ${ }^{2}$, Sebastião de Campos Valadares Filho ${ }^{3}$, Rilene Ferreira Diniz \\ Valadares $^{4}$, Fernanda Helena Martins Chizzotti ${ }^{2}$, José Maurício de Souza Campos ${ }^{3}$, Marcos \\ Inácio Marcondes ${ }^{5}$, Mozart Alves Fonseca ${ }^{6}$
}

\footnotetext{
1 Parcialmente financiado pelo CNPq/FAPEMIG.

2 Doutorando em Zootecnia - UFV.

${ }^{3}$ Departamento de Zootecnia - UFV.

4 Departamento de Medicina Veterinária - UFV.

${ }^{5}$ Mestrando em Zootecnia - UFV.

${ }^{6}$ Graduando em Zootecnia - UFV, bolsista CNPq.
}

RESUMO - Objetivou-se avaliar a influência do peso vivo de novilhas sobre o consumo e a digestibilidade da MS, MO, $\mathrm{EE}, \mathrm{PB}$, fibra em detergente neutro corrigida para cinzas e proteína (FDNcp) e carboidratos não-fibrosos corrigidos (CNFcp), os consumos de NDT e de proteína degradada no rúmen (PDR), a produção de proteína microbiana e a excreção de compostos nitrogenados na urina e comparar as metodologias de coleta spot e de coleta total de urina. Foram utilizadas 22 novilhas com cinco diferentes pesos $(523,453,315,235$ e $118 \mathrm{~kg})$, distribuídas em delineamento inteiramente casualizado, com cinco tratamentos (P523, P453, P315, P235 e P118). A alimentação foi constituída de silagem de milho e concentrado, fornecido na proporção de $1,5 \mathrm{~kg} /$ dia (tratamentos P523, P453, P315 e P235) ou $2 \mathrm{~kg} /$ dia (tratamento P118). Os consumos dos nutrientes em $\mathrm{kg} / \mathrm{dia}$ e em \%PV aumentaram e diminuíram linearmente, respectivamente, com o aumento do peso dos animais. As digestibilidades da MS, MO e o teor de NDT não diferiram entre os tratamentos, enquanto as de PB e FDNcp foram distintas entre os tratamentos, sendo maior e menor, respectivamente, no tratamento P118. A excreção de uréia na urina (em mg/kgPV) foi maior no tratamento P118, variando com o peso vivo e com o consumo de PB e PDR. A produção microbiana, estimada pela excreção urinária de derivados de purinas, não diferiu entre as metodologias de coleta spot e coleta total de urina, sendo menor no tratamento P118. A coleta de urina spot pode ser utilizada para estimativa da excreção de compostos nitrogenados na urina, independentemente do peso vivo. A quantidade de nutrientes ingeridos diariamente aumenta com o peso vivo, entretanto, o consumo desses nutrientes, expresso em $\% \mathrm{PV}$, diminui à medida que o peso vivo aumenta.

Palavras-chave: FDNcp, Holandês, N-uréico no soro, proteína microbiana, amostra spot

\section{Intake, digestibility and urinary excretion of urea and purine derivatives in heifers with different body weights}

\begin{abstract}
The objective of this trial was to evaluate the effect of body weight (BW) of heifers on intake, apparent digestibility of nutrients, microbial protein synthesis, ruminal metabolism, and urinary excretion of nitrogenous compounds The spot urine sampling and the total collection of urine techniques were used to estimate microbial N flow. Twenty-two heifers with different body weights $(523,453,315,235$ and $118 \mathrm{~kg})$ were used in a completely randomized design and assigned to the following treatments: BW523, BW453, BW315, BW235 or BW118. Animals were fed corn silage ad libitum plus $1.5 \mathrm{~kg} / \mathrm{day}$ of concentrate on treatments BW523, BW453, BW315 and BW235 and $2 \mathrm{~kg}$ /day on BW118 treatment. Intake of nutrients increased linearly from treatment BW118 to BW523. However, the opposite was observed when DMI was expressed as percentage of BW. Digestibilities of DM and OM and dietary TDN did not differ among treatments but digestibilities of CP and NDF corrected for ash and protein $\left(\mathrm{NDF}_{\mathrm{ap}}\right)$ were greatest and lowest on BW118 treatment, respectively. The urinary excretion of urea $(\mathrm{mg} / \mathrm{kgBW})$ was higher on BW118 heifers and varied with BW and dietary contents of CP and RDP. Microbial protein synthesis was not affected by sampling methodology and was lowest on treatment BW118. Therefore, spot urine sampling can be used to estimate urinary excretion of nitrogenous compounds and microbial protein synthesis.
\end{abstract}

Key Words: Holstein, microbial protein, NDFap, serum urea nitrogen, spot sample

\section{Introdução}

A recria de novilhas de reposição constitui-se em um importante componente para garantir a evolução genética e produtiva do rebanho. Todavia, em geral, ocorre negligência quanto ao manejo e à alimentação destes animais, com 
suprimento dietético incompatível com sua elevada exigência para crescimento. O elevado custo da alimentação destes animais, os quais ainda não produzem leite para compensar os custos, é o principal responsável por essa situação.

Existe uma correlação positiva entre a ingestão de $\mathrm{Ne}$ a concentração de uréia no soro (Preston et al., 1965). De acordo com Broderick \& Clayton (1997), a concentração elevada de uréia plasmática está relacionada à utilização ineficiente da PB da dieta. A quantidade de uréia sintetizada no fígado é proporcional à concentração de amônia produzida no rúmen e sua concentração sangüínea está diretamente relacionada ao aporte protéico e à relação energia:proteína dietética (Harmeyer \& Martens, 1980). O teor de nitrogênio uréico no soro (NUS) tem sido utilizado para obtenção de informações adicionais sobre a nutrição protéica de ruminantes, por meio da resposta metabólica à determinada dieta. Desse modo, é possível evitar perdas econômicas advindas do fornecimento excessivo de proteína dietética e possíveis prejuízos produtivos, reprodutivos e ambientais.

A proteína sintetizada pelos microrganismos no rúmen possui excelente perfil de aminoácidos e composição pouco variável (NRC, 2001), o que denota a importância do estudo dos mecanismos de síntese protéica microbiana e dos fatores a eles relacionados, visando sua maximização.

Vários estudos confirmam a relação entre produção de proteína microbiana e excreção de derivados de purina na urina (Vagnoni et al., 1997; Rennó et al., 2000).

A excreção de derivados de purina na urina consiste em um método simples e não-invasivo para estimativa da produção de proteína microbiana no rúmen. Nessa técnica, assume-se que os ácidos nucléicos presentes no duodeno são de origem predominantemente microbiana e que, após digestão intestinal dos nucleotídeos purínicos, as purinas absorvidas são catabolizadas e recuperadas proporcionalmente na urina como derivados de purinas.

Segundo Chen \& Gomes (1992), a alantoína e o ácido úrico são os principais derivados de purina presentes na urina de bovinos, pois a alta atividade da enzima xantina oxidase no sangue e nos tecidos converte xantina e hipoxantina em ácido úrico antes da excreção, sendo a excreção de xantina e hipoxantina considerada irrisória em bovinos.

O método baseado na excreção de derivados de purinas urinários requer coleta total de urina, uma técnica laboriosa como rotina experimental. Entretanto, segundo Valadares et al. (1997), é possível simplificar a coleta de urina utilizando-se a excreção de creatinina na urina como indicador da produção urinária, uma vez que essa excreção é relativamente constante em função do peso vivo pelo fato de ser pouco ou não afetada por fatores dietéticos (Chen et al., 1995; Rennó et al., 2000).

Assim, se coletada uma única amostra de urina, denominada amostra spot, e determinada a concentração de creatinina, a excreção de compostos urinários como a uréia e os derivados de purinas (DP) pode ser estimada, facilitando a obtenção de dados experimentais e possibilitando a utilização dessa técnica a campo.

Desta forma, este trabalho foi realizado objetivando-se avaliar a influência do peso vivo sobre o consumo e a digestibilidade dos nutrientes, sobre a produção de proteína microbiana no rúmen, sobre as concentrações de nitrogênio uréico no soro (NUS) e as excreções de N, uréia e derivados de purinas na urina, comparar a excreção urinária de compostos nitrogenados por meio da coleta spot ou da coleta total de urina e determinar a relação entre as concentrações de amônia ruminal e NUS e a relação entre a excreção de N na urina e NUS.

\section{Material e Métodos}

O experimento foi realizado na Unidade de Ensino, Pesquisa e Extensão em Gado de Leite (UEPE-GL) do Departamento de Zootecnia (DZO) da Universidade Federal de Viçosa(UFV), em Viçosa-MG.

A fase de campo foi realizada durante o mês de abril de 2003. Foram utilizadas 22 novilhas com grau de sangue predominantemente Holandês, com diferentes pesos, em sistema de confinamento total em baias individuais, tipo Tie Stall, providas de cocho e bebedouro, distribuídas em delineamento inteiramente casualizado com cinco tratamentos:

tratamento P523 - quatro novilhas com peso médio de $523 \mathrm{~kg}$ (entre $494-546 \mathrm{~kg}$ );

tratamento P453 - cinco novilhas com peso médio de $453 \mathrm{~kg}$ (entre 443 e $471 \mathrm{~kg}$ );

tratamento P315 - quatro novilhas com peso médio de $315 \mathrm{~kg}$ (entre 301 e $345 \mathrm{~kg}$ );

tratamento P235 - cinco novilhas com peso médio de $235 \mathrm{~kg}$ (entre 203 e $274 \mathrm{~kg}$ );

tratamento P118 - quatro novilhas com peso médio de $118 \mathrm{~kg}$ (entre 107 e $137 \mathrm{~kg}$ ).

Os animais foram alimentados duas vezes ao dia ( $8 \mathrm{e}$ $16 \mathrm{~h})$ com silagem de milho à vontade e concentrado em quantidade equivalente à utilizada no manejo do rebanho da UEPE-GL/DZO-UFV. O concentrado, formulado para novilhas de 6 a 12 meses do rebanho UEPE-GL/DZO-UFV, foi fornecido na proporção de $1,5 \mathrm{~kg} /$ dia para as novilhas dos tratamentos P523, P453, P315 e P235 (C1) e de 2 kg/dia para as do tratamento $\mathrm{P} 118$ (C2). A composição média dos alimentos utilizados é apresentada na Tabela 1. 
A duração do período de adaptação foi de sete dias e a do período experimental de dez dias. A alimentação foi fornecida diariamente na forma de mistura completa, de modo a permitir 5\% de sobras, com base na MS total. As sobras foram quantificadas e amostradas diariamente pela manhã e os animais foram pesados ao início e término do período experimental.

No $6^{\circ}$ e $8^{\circ}$ dias do período experimental, foram coletadas amostras de fezes diretamente no reto, às 18 e $6 \mathrm{~h}$, respectivamente, para determinação da digestibilidade aparente total dos nutrientes.

As amostras foram pré-secas em estufa de ventilação forçada, a $65^{\circ} \mathrm{C}$ por 72 horas, processadas em moinho de facas com peneira de $1 \mathrm{~mm}$, elaborando-se uma amostra composta por animal, com base no peso seco de cada subamostra. Foi utilizada a FDAi como indicador interno para estimativa da produção de MS fecal, conforme proposto por Cochran et al. (1986). Entretanto, a incubação ruminal foi feita em sacos de Ankom ${ }^{\circledR}$ (filter bags F57) por 144 horas. Foram incubadas amostras de sobras, fezes e dos ingredientes utilizados nas dietas. No material remanescente da incubação, foi determinada a FDA, conforme descrito por Silva \& Queiroz (2002), e estimados os coeficientes de digestibilidade dos nutrientes $(\mathrm{CD})$ pela equação:

Tabela 1 - Teores de MS, MO, PB, PDR, NIDN, NIDA, EE, FDN, FDNcp, CNF, carboidratos não-fibrosos calculados com FDNcp, FDA, LIG e FDAi dos alimentos, com base na MS

Table 1 - Contents of DM, OM, CP, RDP, NDIN, ADIN, EE, NDF, NDFap, NFC, nonfiber carbohydrates calculated with NDFap (NFCap), $A D F, L I G$, and $i A D F$ of feeds, on DM basis

\begin{tabular}{lrrr}
\hline Item & $\begin{array}{c}\text { Silagem de milho } \\
\text { Corn silage }\end{array}$ & $\begin{array}{c}\text { Concentrado } \\
\text { Concentrate }\end{array}$ \\
\cline { 3 - 4 } & & \multicolumn{1}{c}{$\mathrm{C} 1$} & \multicolumn{1}{c}{$\mathrm{C} 2$} \\
\hline MS (\%) (DM, \%) & 24,93 & 88,59 & 88,59 \\
MO (\%MS) (OM, \%DM) & 94,83 & 94,56 & 94,58 \\
PB (\%MS) (CP, \%DM) & 6,56 & 25,45 & 26,17 \\
PDR (\% PB) (RDP, \% CP) & 76,06 & 69,57 & 65,38 \\
NIDN (\% N total) (NDIN, \% total N) & 17,01 & 4,83 & 4,93 \\
NIDA (\% N total) (ADIN, \% total N) & 10,84 & 2,82 & 2,78 \\
EE (\%MS) (EE, \%DM) & 3,07 & 3,13 & 3,12 \\
FDN (\%MS) (NDF, \%DM) & 54,10 & 9,61 & 9,65 \\
FDNcp (\%MS) (NDFap, \%DM) & 50,33 & 8,66 & 8,68 \\
CNF (\%MS) (NFC, \%DM) & 31,11 & 56,36 & 55,64 \\
CNFcp (\%MS) (NFCap, \%DM) & 34,88 & 57,31 & 56,60 \\
FDA (\%MS) (ADF, \%DM) & 34,43 & 5,29 & 5,19 \\
LIG (\%MS) (LIG, \%DM) & 4,73 & 0,77 & 0,76 \\
FDAi (\%MS) (iADF, \%DM) & 17,90 & 0,42 & 0,42 \\
\hline C1 -Concentrado $\%$ M & &
\end{tabular}

C1 - Concentrado fornecido às novilhas dos tratamentos P523, P453, P315 e P235.

C2 - Concentrado fornecido às novilhas dos tratamentos P118.

C1 - Concentrate fed to heifers on treatments BW523, BW453, BW315, and BW235.

C2 - Concentrate fed to heifers on treatment BW118.
$\mathrm{CD}(\%)=100-100 *[(\%$ de FDAi no alimento $/ \%$ de FDAi nas fezes $) *(\%$ do nutriente nas fezes $/ \%$ do nutriente no alimento)].

Alíquotas de $50 \mathrm{~mL}$ de urina (amostra spot) foram obtidas de todas as novilhas no $7^{\circ}$ dia do período experimental, aproximadamente 4 horas após a alimentação, durante micção estimulada por massagem na vulva. A urina foi filtrada e alíquotas de $10 \mathrm{~mL}$ foram retiradas e diluídas imediatamente em $40 \mathrm{~mL}$ de ácido sulfúrico a $0,036 \mathrm{~N}$, para evitar destruição bacteriana dos derivados de purinas e precipitação de ácido úrico, sendo armazenadas a $-15^{\circ} \mathrm{C}$ para posteriores análises de uréia, alantoína e ácido úrico. Uma amostra de urina pura foi armazenada para determinação dos compostos nitrogenados totais e de creatinina. Concomitantemente, foram obtidas amostras de sangue por punção da veia coccígea, utilizando-se tubo de ensaio com gel separador e acelerador de coagulação. As amostras foram imediatamente centrifugadas a $5.000 \mathrm{rpm}$ por 15 minutos para obtenção do soro, que foi armazenado em congelador para posteriores análises de creatinina e uréia.

No $9^{\circ}$ dia do período experimental, foi realizada coleta total de urina de cada animal durante 24 horas, utilizando-se cateteres de Folley de números 14 a 26, de acordo com o tamanho da novilha, acoplados a mangueiras que conduziram a urina até recipientes plásticos contendo $500 \mathrm{~mL}$ de $\mathrm{H}_{2} \mathrm{SO}_{4} 20 \%$. Após a coleta, procedeu-se à quantificação do volume urinário diário, processando as amostras da mesma forma descrita para a coleta spot.

Amostras de conteúdo ruminal foram coletadas 4 horas após a alimentação matinal no $10^{\circ}$ dia, utilizando-se mangueira de borracha introduzida pelo esôfago, com uma das extremidades acoplada a kitassato e bomba de vácuo, para determinação do $\mathrm{pH}$ e da concentração de amônia do líquido ruminal.

O processamento das amostras de alimentos, sobras e fezes e as análises de MS, cinzas, nitrogênio total, NIDA, NIDN, EE e FDA foram feitas segundo procedimentos descritos por Silva \& Queiroz (2002). A FDN foi determinada pela técnica da autoclave, segundo Rennó et al. (2002), sendo quantificados os teores de PB e cinzasda FDN, conforme Silva \& Queiroz (2002), e subtraindo-os da FDN para determinação da FDN corrigida (FDNcp). Os CNF e CNFcp foram calculados por meio da equação (Weiss, 1999): $\mathrm{CNFcp}=100-(\% \mathrm{~PB}+\% \mathrm{EE}+\%$ Cinzas + $\%$ FDNcp), porém utilizando-se a FDN sem correção para o cálculo dos CNF.

Foram calculados os teores de PDR, conforme recomendações do NRC (2001); as concentrações de N-NH 3 nas amostras do líquido ruminal, segundo técnica de Fenner 
(1965), adaptada por Vieira (1980); e a concentração de uréia na urina e no soro, pelo método diacetil modificado (kits comerciais).

A creatinina foi determinada nas amostras spot de urina com o uso de kits comerciais (Labtest ${ }^{\circledR}$ ), pelo método de ponto final, com utilização de picrato e acidificante. A excreção diária de creatinina (EC) foi estimada por: EC $(\mathrm{mg} / \mathrm{dia})=32,27-0,01093 * \mathrm{PV}(\mathrm{kg})$ (Chizzotti et al., 2004). A concentração de creatinina na amostra spot foi utilizada para estimar o volume urinário e a excreção dos demais compostos urinários, para comparação dos valores obtidos na amostra spot com os observados na coleta total.

As análises de alantoína e de ácido úrico na urina foram feitas pelo método colorimétrico, conforme metodologia de Fujihara et al. (1987), descrita por Chen \& Gomes (1992). A excreção total de DP foi calculada pela soma das quantidades de alantoína e ácido úrico excretadas na urina, expressas em mmol/dia. As purinas absorvidas (Pabs, mmol/dia) foram calculadas a partir da excreção de derivados de purinas (DP, mmol/dia) utilizando-se a equação: $\mathrm{DP}=0,84$ * Pabs $+0,236 * \mathrm{PV}^{0,75}$, em que 0,84 é a recuperação de purinas absorvidas como derivados de purina e $0,236 *$ $\mathrm{PV}^{0,75}$, a excreção de derivados de purina de origem endógena (Orellana Boero et al., 2001). A síntese ruminal de compostos nitrogenados (Nmic, g/dia) foi calculada em função das purinas absorvidas (Pabs, $\mathrm{mmol} / \mathrm{dia}$ ), utilizando-se a equação (Chen \& Gomes, 1992): Nmic $=(70 *$ Pabs $) /(0,83$
* 0,134* 1000), em que 70 é o conteúdo de $\mathrm{N}$ nas purinas ( $\mathrm{mgN} / \mathrm{mol}), 0,134$ a relação $\mathrm{N}$ purina : $\mathrm{N}$ total nas bactérias (Valadares et al. 1999) e 0,83 a digestibilidade das purinas microbianas.

Os resultados foram avaliados por meio de análises de variância e regressão, utilizando-se o Sistema de Análises Estatísticas e Genéticas (SAEG), UFV (1998), aplicando-se o teste $\mathrm{t}$ a $5 \%$ de probabilidade para comparação das metodologias de coleta de urina.

\section{Resultados e Discussão}

Na Tabela 2, são apresentados os consumos médios dos nutrientes pelas novilhas de diferentes pesos e as respectivas equações de regressão.

A proporção de volumoso das dietas fornecidas foram de 85,$69 ; 84,16 ; 81,53 ; 78,04$ e 53,05\%, respectivamente, para os tratamentos P523, P453, P315, P235 e P118. O consumo dos nutrientes ( $\mathrm{kg} / \mathrm{dia})$ apresentou comportamento linear crescente com o peso vivo. O NRC (1996) descreve alta correlação entre o consumo de MS e o peso do animal. Quando o peso animal foi ajustado, para diminuir os efeitos de sexo, idade e tamanho à maturidade do animal, o peso foi responsável por aproximadamente $60 \%$ da variação no consumo (NRC, 1996).

O consumo de MS, em porcentagem do PV, foi negativamente correlacionado ao PV. A composição corporal,

Tabela 2 - Médias, equações de regressão e coeficientes de variação (CV) obtidos para os consumos diários de MS, MO, PB, PDR, EE, FDNcp, carboidratos não-fibrosos corrigidos (CNFcp) e NDT e consumos de MS e FDN, em \%PV, para cada tratamento

Table 2 - Means, regression equations and coefficients of variation of the daily intakes of DM, OM, CP, RDP, EE, NDFap, nonfiber carbohydrates calculated using NDFap (NFCap) and TDN and intakes of DM and NDF, expressed in percentage of body weight for each treatment

\begin{tabular}{|c|c|c|c|c|c|c|c|}
\hline \multirow[t]{2}{*}{ Item } & \multicolumn{5}{|c|}{$\begin{array}{c}\text { Tratamento } \\
\text { Treatment }\end{array}$} & \multirow[t]{2}{*}{$\begin{array}{l}\text { Equação } \\
\text { Equation }\end{array}$} & \multirow[t]{2}{*}{ CV $(\%)$} \\
\hline & P 523 & P 453 & P 315 & P 235 & P 118 & & \\
\hline \multicolumn{8}{|c|}{$\begin{array}{l}\text { Consumo }(\mathrm{kg}) \\
\text { Intake }(\mathrm{kg})\end{array}$} \\
\hline $\operatorname{MS}(D M)$ & 7,72 & 7,27 & 6,30 & 5,20 & 3,28 & 1 & 8,12 \\
\hline MO (OM) & 7,31 & 6,89 & 5,97 & 4,92 & 3,11 & 2 & 8,14 \\
\hline $\mathrm{PB}(C P)$ & 0,75 & 0,73 & 0,66 & 0,59 & 0,55 & 3 & 5,41 \\
\hline PDR $(R D P)$ & 0,57 & 0,55 & 0,50 & 0,44 & 0,39 & 4 & 5,42 \\
\hline $\mathrm{EE}$ & 0,24 & 0,22 & 0,19 & 0,16 & 0,11 & 5 & 8,09 \\
\hline FDNcp (NDFap) & 3,34 & 3,11 & 2,56 & 2,04 & 0,92 & 6 & 9,58 \\
\hline CNFcp (NFCap) & 2,98 & 2,82 & 2,54 & 2,14 & 1,53 & 7 & 7,61 \\
\hline $\mathrm{NDT}(T D N)$ & 5,00 & 4,64 & 4,21 & 3,45 & 2,23 & 8 & 8,40 \\
\hline \multicolumn{8}{|c|}{$\begin{array}{c}\text { Consumo }(\% \mathrm{PV}) \\
\text { Intake }(\% B W)\end{array}$} \\
\hline $\operatorname{MS}(D M)$ & 1,48 & 1,61 & 1,94 & 2,15 & 2,77 & 9 & 7,39 \\
\hline FDN (NDF) & 0,64 & 0,69 & 0,79 & 0,84 & 0,77 & 10 & 9,51 \\
\hline
\end{tabular}

1) $\left.\left.\left.\hat{Y}=2,3876+0,0108^{*} P V\left(r^{2}=0,94\right) ; 2\right) \hat{Y}=2,2582+0,0102^{*} P V\left(r^{2}=0,94\right) ; 3\right) \hat{Y}=0,4796+0,000526^{*} P V\left(r^{2}=0,97\right) ; 4\right) \hat{Y}=0,3300+0,0004737^{*} P V\left(r^{2}=0,89\right)$;

5) $\left.\left.\left.\hat{Y}=0,0821+0,0003109^{*} \mathrm{PV}\left(r^{2}=0,95\right) ; 6\right) \hat{\mathrm{Y}}=0,4657+0,005825^{*} \mathrm{PV}\left(\mathrm{r}^{2}=0,93\right) ; 7\right) \hat{\mathrm{Y}}=1,2307+0,003534^{*} \mathrm{PV}\left(\mathrm{r}^{2}=0,94\right) ; 8\right) \hat{\mathrm{Y}}=1,7149+0,006596^{*} \mathrm{PV}$ $\left.\left.\left(r^{2}=0,94\right) ; 9\right) \hat{Y}=3,0028-0,003068^{*} P V\left(r^{2}=0,93\right) ; 10\right) \hat{Y}=0,8795-0,0003989^{*} P V\left(r^{2}=0,66\right)$. 
principalmente a porcentagem de gordura, é apontada como um dos principais fatores metabólicos relacionados ao controle da ingestão (NRC, 1987). Segundo Fox et al. (1988), citados pelo NRC (1996), o consumo de MS diminui $2,7 \%$ para cada unidade percentual de aumento no teor de gordura corporal. Possivelmente, a leptina, produzida no tecido adiposo, estaja envolvida neste controle. O tecido adiposo é o tecido de desenvolvimento mais tardio, de modo que animais mais leves, mais distantes do peso à maturidade, apresentam menor proporção de gordura no corpo e, portanto, ingerem mais MS em porcentagem do peso vivo.

As taxas de passagem estimadas pelas equações propostas pelo NRC (2001) foram de 4,1; 4,21; 4,49; 4,7 e 5,66\%/ hora, respectivamente, para os tratamentos P523, P453, P315, P235 e P118, possibilitando maior consumo, em relação ao peso vivo, dos animais de menor peso.

Conforme demonstrado na Tabela 3 , as digestibilidades da MS, MO e CNFcp foram similares entre os tratamentos, embora o consumo tenha aumentado.

Considerando que maior consumo de $\mathrm{MS} / \mathrm{kgPV}$ tende a elevar a taxa de passagem da digesta, o maior consumo em \%PV não influenciou a digestibilidade da MS no tratamento $\mathrm{P} 118$. Como a silagem foi fornecida à vontade $\mathrm{e}$ o concentrado foi oferecido na mesma quantidade para os animais dos tratamentos P523, P453, P315 e P235 e em maiores quantidades para os do tratamento $\mathrm{P} 118$, a relação volumoso:concentrado foi menor para os animais mais leves, os quais consumiram dieta menos fibrosa, porém menos digestível em virtude da passagem mais rápida pelo trato gastrintestinal.

Foi observada maior digestibilidade da PB para as novilhas menores (P118), possivelmente em decorrência dos maiores teores de PDR e PB da dieta. A dieta das novilhas do tratamento $\mathrm{P} 118$ apresentou maior teor de PDR (Tabela 2) e maior degradação ruminal efetiva da proteína em relação à dos demais tratamentos. Segundo o NRC (1985), a excreção de N-metabólico fecal diminui à medida que a concentração dietética de proteína aumenta e/ou a de MO indigestível diminui. Os compostos nitrogenados fecais podem ser divididos em N-dietético, N-microbiano e $\mathrm{N}$-endógeno indigestíveis. O consumo de dietas com maior teor de PB implica aumento da quantidade de N-dietético indigestível nas fezes e conseqüente diminuição na proporção de $\mathrm{N}$-endógeno fecal em relação às demais frações. Assim, a proporção $\mathrm{N}$-dietético indigestível fecal:excreção total de $\mathrm{N}$ nas fezes aumenta, elevando a digestibilidade aparente da PB (Van Soest, 1994).

A digestibilidade da FDN foi inferior no tratamento P118 (118 kg), no qual os animais apresentaram maior consumo em $\% \mathrm{PV}$ e consumiram dietas com maior proporção de concentrado, o que pode ter ocasionado maior taxa de passagem da digesta, afetando negativamente a digestão da fração fibrosa da ração. Além disso, o maior consumo de concentrado resultou em menor $\mathrm{pH}$ ruminal (Tabela 6), podendo ter diminuído a atividade das bactérias fibrolíticas.

As médias das excreções diárias de uréia e as concentrações de $\mathrm{N}$-uréico no soro e na urina e de $\mathrm{N}-\mathrm{NH}_{3}$ no rúmen são apresentadas na Tabela 4 . A excreção de urina foi altamente variável (coeficiente de variação de 55\%), mas não foram detectadas diferenças entre as diversas faixas de peso.

As concentrações de NUS e $\mathrm{NH}_{3}$ ruminal e a excreção urinária de uréia em $\mathrm{mg} / \mathrm{kgPV}$ foram negativamente correlacionadas ao peso das novilhas. As porcentagens de PB dietética foram, em média, de 9,68; 9,99; 10,55; 11,33 e $16,96 \%$ da MS para os tratamentos P523, P453, P315, P235

Tabela 3 - Médias e coeficientes de variação (CV) obtidos para os coeficientes de digestibilidade aparente total de MS, MO, PB, EE, FDNcp e CNFcp e teores de NDT dietéticos para cada tratamento

Table 3 - Means and coefficients of variation (CV) of the total tract apparent digestibilities coefficients of DM, OM, CP, EE, NDFap, and NFCap and dietary contents of TDN for each treatment

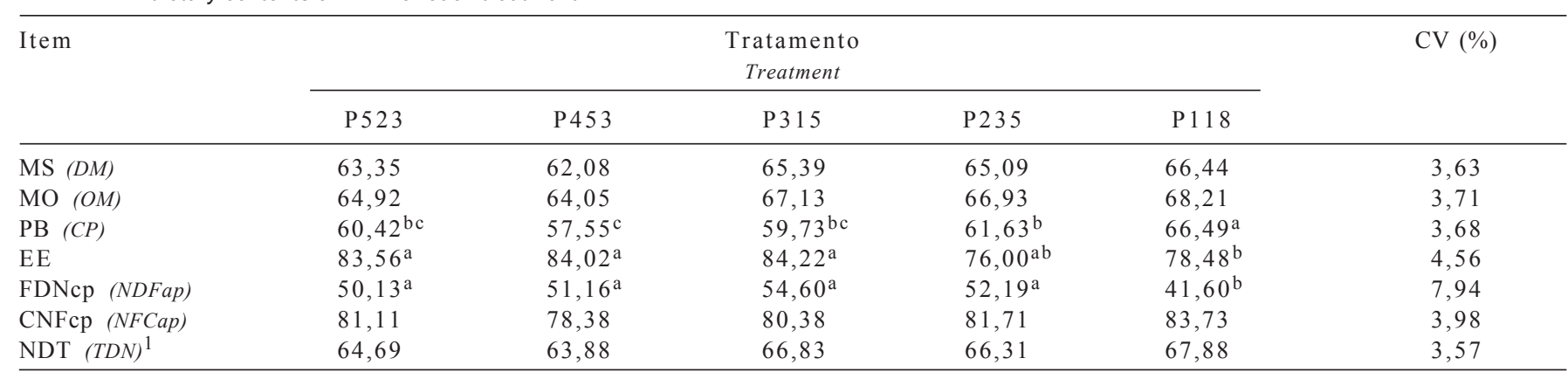

a, b, c Médias na mesma linha seguidas de mesma letra não diferem pelo teste de Newman Keuls a $5 \%$ de probabilidade.

1 expresso em \% da MS.

a, b, $c$ Means in a row followed by the same letter did not differ by Newman Keuls test at $5 \%$ of probability.

1 expressed as \% of DM. 
Tabela 4 - Médias e coeficientes de variação (CV) obtidos para os volumes urinários diários (VUR), as concentrações de $\mathrm{N}$-amoniacal no rúmen ( $\left.\mathrm{N}-\mathrm{NH}_{3}\right)$, N-uréico no soro (NUS) e as excreções de $\mathrm{N}$-total (NU) e N-uréico na urina (NUU) entre os tratamentos

Table 4 - $\quad$ Means and coefficients of variation (CV) for daily urine volume (UV), ruminal ammonia $\mathrm{N}$ concentration ( $\mathrm{NH}_{3}-\mathrm{N}$ ), serum urea $\mathrm{N}$ concentration (SUN) and daily excretions of total urinary nitrogen (UN) and urinary urea nitrogen (UUN) of each treatment

\begin{tabular}{|c|c|c|c|c|c|c|}
\hline \multirow[t]{2}{*}{ Item } & \multicolumn{5}{|c|}{$\begin{array}{c}\text { Tratamento } \\
\text { Treatment }\end{array}$} & \multirow[t]{2}{*}{$\mathrm{CV}(\%)$} \\
\hline & P 523 & P 453 & P3 15 & P23 5 & P 118 & \\
\hline \multirow[t]{2}{*}{ VUR $(\mathrm{kg})(U V, \mathrm{~kg})$} & 22,23 & 17,47 & 22,98 & 14,82 & 11,30 & 55,45 \\
\hline & \multicolumn{5}{|c|}{$\begin{aligned} \text { Concentração } & (\mathrm{mg} / \mathrm{dL}) \\
\text { Concentration } & (m g / d L)\end{aligned}$} & \\
\hline \multirow{2}{*}{ NUS $(S U N)$} & $\begin{array}{l}4,60^{\mathrm{b}} \\
4,08^{\mathrm{b}}\end{array}$ & $\begin{array}{l}5,02^{\mathrm{b}} \\
4,14^{\mathrm{b}}\end{array}$ & $\begin{array}{l}5,58^{\mathrm{b}} \\
4,11^{\mathrm{b}}\end{array}$ & $\begin{array}{l}5,26^{\mathrm{b}} \\
6,36^{\mathrm{b}}\end{array}$ & $\begin{array}{l}11,81^{\mathrm{a}} \\
13,89^{\mathrm{a}}\end{array}$ & $\begin{array}{l}25,64 \\
32,12\end{array}$ \\
\hline & \multicolumn{5}{|c|}{$\begin{array}{l}\text { Excreção diária } \\
\text { Daily excretion }\end{array}$} & \\
\hline $\mathrm{NU}(\mathrm{g})(U N, \mathrm{~g})$ & $40,99^{a b c}$ & $45,53^{\mathrm{ab}}$ & $48,69^{\mathrm{a}}$ & $31,09^{b c}$ & $28,44^{\mathrm{c}}$ & 22,95 \\
\hline NUU $(g)(U U N, g)$ & 23,98 & 31,16 & 32,40 & 22,37 & 26,76 & 19,24 \\
\hline $\mathrm{NU}(\mathrm{mg} / \mathrm{kgPV})(U N, \mathrm{mg} / \mathrm{kg} B W)$ & $77,68^{\mathrm{d}}$ & $100,16^{\mathrm{cd}}$ & $149,69^{\mathrm{b}}$ & $129,11^{\mathrm{bc}}$ & $241,04^{\mathrm{a}}$ & 19,37 \\
\hline $\mathrm{NUU}(\mathrm{mg} / \mathrm{kgPV})(U U N, \mathrm{mg} / \mathrm{kgBW})$ & $45,85^{\mathrm{c}}$ & $68,67^{\mathrm{bc}}$ & $100,00^{\mathrm{b}}$ & $92,40^{\mathrm{b}}$ & $227,37^{\mathrm{a}}$ & 20,97 \\
\hline
\end{tabular}

a, b, c, d Médias na mesma linha seguidas de letras diferentes diferem pelo teste de Newman Keuls a $5 \%$ de probabilidade. $a, b, c, d$ Means in the same row followed by different letter differ by Newman Keuls test at $5 \%$ of probability.

e P118, respectivamente. Valadares et al. (1997), em estudo realizado com novilhos alimentados com dietas contendo 7,$0 ; 9,5 ; 12,0$ e 14,5\% de PB observaram níveis de N-uréico no plasma (NUP) de 8,$1 ; 9,1 ; 15,7$ e 19,5 mg/dL, respectivamente, e também notaram influência do teor de PB dietética sobre a concentração de amônia ruminal e a excreção de $\mathrm{N}$-uréico urinário. Maiores concentrações de NUP e $\mathrm{NH}_{3}$ ruminais em dietas mais protéicas também foram detectadas por Preston et al. (1965) e Rennó et al. (2003).

Como a proporção de PDR e o consumo de PB em relação à energia dietética foram maiores nas novilhas mais leves (as relações PB consumida:NDT consumido foram de 14,$97 ; 15,65 ; 15,8 ; 17,09$ e 25,07\% para os tratamentos $\mathrm{P} 523$, P453, P315, P235 e P118, respectivamente), as concentrações de $\mathrm{NH}_{3}$ ruminal e de NUS e, conseqüentemente, as excreções urinárias, em mg/kgPV, de nitrogênio total (NU) e N-uréico (NUU) nesses animais (P118) foram maiores.

Os coeficientes de correlação entre NUS e NU e N-NH foram, respectivamente, 0,87 e 0,84 , evidenciando a correlação entre estes parâmetros e confirmando os relatos de Broderick \& Clayton (1997). Considerando que incorreto balanceamento de proteína e aminoácidos na dieta resulta em aumentos na concentração de uréia plasmática e na excreção urinária de compostos nitrogenados, esforços têm sido feitos para se estimar a excreção urinária de N (NU) a partir do NUS. A partir dos dados obtidos neste trabalho, foram ajustadas equações de regressão para estimativa da excreção de NU por meio da concentração de NUS: NU $(\mathrm{mg} / \mathrm{kg} \mathrm{PV} / \mathrm{dia})=12,7504 * * \mathrm{NUS}(\mathrm{mg} / \mathrm{dL})+55,6131\left(\mathrm{r}^{2}=0,76\right)$.
Também foi desenvolvida a seguinte equação para se estimar a concentração de amônia no rúmen $\left(\mathrm{N}-\mathrm{NH}_{3}\right)$ 4 horas após a alimentação, a partir da concentração de NUS: $\mathrm{N}-\mathrm{NH}_{3}=0,6137 * * \mathrm{NUS}+2,4051\left(\mathrm{r}^{2}=0,69\right)$. Ambas as equações tiveram o coeficiente de regressão e o intercepto diferentes de um e zero, respectivamente, pelo teste t a $1 \%$ de probabilidade.

Conforme descrito na Tabela 5, apenas o volume urinário foi significativamente distinto entre as duas metodologias de coleta, realizadas em datas diferentes. Contudo, esta diferença não influenciou a estimativa da excreção dos demais compostos urinários pela amostra spot.

A excreção de urina foi pouco correlacionada à excreção dos compostos urinários estudados. Desta forma, uma mudança no volume urinário ocasionada pelo consumo de água, por exemplo, pode alterar a concentração urinária sem, no entanto, alterar a excreção diária de compostos urinários como os DP, a uréia e a creatinina.

Chen et al. (1995), em estudo da variação diurna das concentrações de creatinina e DP em novilhas submetidas a diferentes freqüências de alimentação, reportaram pequenas oscilações na concentração destes parâmetros e verificaram que a variação na concentração de creatinina na urina foi similar à observada nos DP. Assim, os autores não observaram diferenças na relação DP:creatinina nos diferentes tratamentos e tempos de amostragem e concluíram que uma amostra de urina coletada ao longo do dia (spot) poderia ser utilizada para estimativa da excreção diária de DP na urina. 
Tabela 5 - Médias e probabilidade $(\mathrm{P})$, obtidas pela coleta total e estimadas pela amostra spot, do volume urinário (VUR), das excreções de N uréia (NUU), alantoína $(A L A)$, ácido úrico $(A c U)$ e derivados de purina (DP), porcentagem de alantoína urinária nos DP (ALA:DP), purinas microbianas absorvidas (Pabs), compostos nitrogenados microbianos (Nmic), proteína microbiana sintetizada no rúmen (PBmic) e eficiência microbiana (Efic)

Table 5 - Means and probabilities (P) of urinary volume (UV), urinary excretions of urea $N(U N)$, allantoin (ALLA), uric acid (UAC) and purine derivatives $(P D)$, proportion of allantoin on $P D(A L L A: P D)$, absorbed microbial purines (Pabs), microbial nitrogen (micN), microbial protein synthesis (micP) and microbial efficiency (Efic) obtained by total urine collection (observed) or by spot samples of urine (estimated)

\begin{tabular}{|c|c|c|c|}
\hline \multirow[t]{2}{*}{ Item } & \multicolumn{2}{|c|}{$\begin{array}{l}\text { Média } \\
\text { Mean }\end{array}$} & \multirow[t]{2}{*}{$\mathrm{P}$} \\
\hline & $\begin{array}{l}\text { Obtida } \\
\text { Observed }\end{array}$ & $\begin{array}{l}\text { Estimada } \\
\text { Estimated }\end{array}$ & \\
\hline $\begin{array}{l}\text { VUR (L/dia) } \\
U V \text { (L/day) }\end{array}$ & 17,61 & 32,28 & $*$ \\
\hline $\begin{array}{l}\text { NUU (mg/kgPV/dia) } \\
U N \text { (mg/kgBW/day) }\end{array}$ & 104,46 & 80,67 & ns \\
\hline $\begin{array}{l}\text { ALA }(\mathrm{mmol} / \mathrm{dia}) \\
\text { ALLA }(\mathrm{mmol} / \text { day })\end{array}$ & 122,04 & 112,96 & ns \\
\hline $\begin{array}{l}\mathrm{AcU}(\mathrm{mmol} / \mathrm{dia}) \\
\text { UAc (mmol/day })\end{array}$ & 12,08 & 13,33 & ns \\
\hline $\begin{array}{l}\text { DP }(\mathrm{mmol} / \mathrm{dia}) \\
P D(\text { mmol/day })\end{array}$ & 134,12 & 126,25 & ns \\
\hline $\begin{array}{l}\text { ALA:DP }(\%) \\
A L L A: P D(\%)\end{array}$ & 90,84 & 89,30 & ns \\
\hline $\begin{array}{l}\text { Pabs (mmol/dia) } \\
\text { Pabs (mmol/day) }\end{array}$ & 136,51 & 127,30 & ns \\
\hline $\begin{array}{l}\text { Nmic (g/dia) } \\
m i c N \text { (g/day) }\end{array}$ & 85,92 & 80,12 & ns \\
\hline $\begin{array}{l}\text { Efic }(\mathrm{g} \mathrm{PBmic} / \mathrm{kg} \text { NDT}) \\
\text { Efic }(g \text { mic } C P / \mathrm{kg} T D N)\end{array}$ & 139,45 & 132,48 & ns \\
\hline
\end{tabular}

Rennó et al. (2003) detectaram diferença no volume urinário de novilhos, mas não notaram diferenças nas excreções de DP obtidas por coleta spot ou total, sugerindo que a amostra spot pode ser utilizada como método rápido e eficaz para determinação do fluxo de proteína microbiana.

As excreções diárias de alantoína e DP e, conseqüentemente, a produção de proteína microbiana, foram inferiores nas novilhas de menor peso (Tabela 6). O mesmo foi observado para o consumo de MS (em kg/dia); logo, os animais que consumiram mais apresentaram maior síntese ruminal de microrganismos, como resultado do maior suprimento de substratos fermentáveis. De acordo com Van Soest (1994), aumentos na ingestão proporcionam maior escape de microrganismos para o duodeno.

A proporção de alantoína nos DP não diferiu entre os tratamentos (média de 91,75\%), sendo próxima aos valores obtidos por Rennó (2003), de 91,70 e 93,36\%, em dois experimentos. Valores inferiores, de 87,$90 ; 87,17$ e $85 \%$ foram encontrados por Leão et al. (2004, 2005), Rennó et al. (2000) e Verbic et al. (1990), respectivamente.

A eficiência de síntese microbiana não diferiu entre os tratamentos, porém, foram observadas diferenças numéricas entre os animais de diferentes faixas de peso. As disponibilidades ruminais de energia e $\mathrm{N}$ são os fatores nutricionais que mais afetam o crescimento microbiano (Clark et al., 1992) e, portanto, a relação volumoso:concentrado dietética poderia influenciar o crescimento microbiano. A taxa de passagem é influenciada pelo consumo de alimento e por suas propriedades intrínsecas, como o tamanho de partícula

Tabela 6 - Médias e coeficientes de variação (CV, \%) obtidos das excreções urinárias de alantoína (ALA), ácido úrico (AcU) e derivados de purinas (DP), da porcentagem de alantoína nos DP (ALA:DP), das purinas absorvidas (Pabs), do nitrogênio microbiano (Nmic), da proteína microbiana sintetizada no rúmen ( $\mathrm{PBmic}$ ), da eficiência microbiana (Efic) e do pH ruminal entre os tratamentos

Table 6 - Means and coefficients of variation (CV, \%) for urinary excretions of allantoin (ALLA), uric acid (UAC) and purine derivatives (PD), proportion of allantoin on PD (ALLA:PD), absorbed microbial purines (Pabs), microbial nitrogen (micN), microbial protein synthesis in the rumen (micP), microbial efficiency (Efic), and ruminal $\mathrm{pH}$ of each treatment

\begin{tabular}{|c|c|c|c|c|c|c|}
\hline \multirow[t]{2}{*}{ Item } & \multicolumn{5}{|c|}{$\begin{array}{c}\text { Tratamento } \\
\text { Treatment }\end{array}$} & \multirow[t]{2}{*}{$\mathrm{CV}(\%)$} \\
\hline & P 523 & P 453 & P 315 & P 235 & P 118 & \\
\hline ALA $(A L L A)^{1}$ & $148,16^{\mathrm{a}}$ & $145,55^{\mathrm{a}}$ & $126,49^{\mathrm{ab}}$ & $111,57^{\mathrm{b}}$ & $75,21^{\mathrm{c}}$ & 14,33 \\
\hline $\operatorname{AcU}(U A c)^{1}$ & $16,68^{\mathrm{a}}$ & $12,09^{b}$ & $12,74^{\mathrm{b}}$ & $10,84^{\mathrm{b}}$ & $8,35^{\mathrm{b}}$ & 20,35 \\
\hline $\mathrm{DP}(P D)^{1}$ & $164,84^{\mathrm{a}}$ & $157,64^{\mathrm{a}}$ & $139,23^{a b}$ & $122,40^{\mathrm{b}}$ & $83,56^{\mathrm{c}}$ & 13,20 \\
\hline ALA:DP (ALLA:PD) & 89,63 & 92,38 & 90,75 & 91,04 & 89,95 & 2,09 \\
\hline Pabs $(P a b s)^{2}$ & $163,59^{\mathrm{a}}$ & $158,18^{\mathrm{a}}$ & $142,50^{\mathrm{a}}$ & $126,94^{\mathrm{a}}$ & $88,34^{\mathrm{b}}$ & 14,69 \\
\hline $\operatorname{Nmic}(\operatorname{MicN})^{2}$ & $102,96^{\mathrm{a}}$ & $99,55^{\mathrm{a}}$ & $89,68^{\mathrm{a}}$ & $79,90^{\mathrm{a}}$ & $55,60^{\mathrm{b}}$ & 14,69 \\
\hline $\operatorname{PBmic}(\operatorname{mic} C P)^{2}$ & $643,50^{\mathrm{a}}$ & $622,21^{\mathrm{a}}$ & $560,53^{\mathrm{a}}$ & $499,35^{\mathrm{a}}$ & $347,49^{b}$ & 14,69 \\
\hline Efic $^{3}$ & 128,93 & 134,14 & 133,60 & 143,96 & 156,81 & 11,69 \\
\hline $\mathrm{pH}$ ruminal (ruminal $\mathrm{pH}$ ) & $6,52^{\mathrm{a}}$ & $6,58^{a}$ & $6,57^{\mathrm{a}}$ & $6,78^{\mathrm{a}}$ & $6,10^{\mathrm{b}}$ & 3,43 \\
\hline
\end{tabular}

a, b, c, d médias na mesma linha seguidas da mesma letra não diferem pelo teste de Newman Keuls a $5 \%$ de probabilidade.

$1 \mathrm{mmol} / \mathrm{dia} ;{ }^{2} \mathrm{~g} / \mathrm{dia} ;{ }^{3} \mathrm{~g}$ de PBmic/kg de NDT consumido.

a, b, c, d means in the same row followed by the same letter did not differ by the Newman Keuls test at $5 \%$ of probability.

${ }^{1} \mathrm{mmol} / \mathrm{day} ;{ }^{2} \mathrm{~g} /$ day; ${ }^{3} \mathrm{~g}$ micCP $/ \mathrm{kg}$ of ingested TDN. 
e a densidade. Dessa forma, a taxa de passagem de concentrados é reconhecidamente superior. Taxas mais rápidas de crescimento microbiano atribuídas à maior disponibilidade de nutrientes, associadas à passagem mais rápida de microrganismos para o abomaso, podem reduzir os requisitos de mantença da microbiota ruminal (Clark et al., 1992) e incrementar a eficiência microbiana.

Os valores de $\mathrm{pH}$ ruminal foram inferiores nas novilhas do tratamento $\mathrm{P} 118$, que consumiram maior proporção de carboidratos de rápida fermentação. Coelho da Silva \& Leão (1979) relataram que valores de $\mathrm{pH}$ inferiores a 6,0 podem acarretar diminuição da atividade das bactérias fibrolíticas, reduzindo, conseqüentemente, a degradação da fibra.

\section{Conclusões}

A quantidade diária de nutrientes ingeridos eleva com o aumento do peso vivo dos animais, entretanto, o consumo destes nutrientes, em \% PV, pelos animais diminui à medida que o peso vivo aumenta. Logo, a predição do consumo de MS em função de um coeficiente fixo, em porcentagem do peso vivo, não é adequada para estimar o consumo por animais com pesos distantes da faixa de peso na qual o coeficiente foi gerado.

A concentração de N-uréico no soro é afetada pelo consumo de matéria seca, proteína bruta, proteína degradada no rúmen e, conseqüentemente, pelo peso vivo, não sendo apropriada a utilização de um valor constante de NUS como padrão para avaliação do status protéico de novilhas de diferentes pesos.

A coleta spot pode ser utilizada para estimativa da excreção diária de derivados de purinas e de uréia na urina em novilhas, independentemente do peso vivo.

\section{Literatura Citada}

BRODERICK, G.A.; CLAYTON, M.K. A statistical evaluation of animal and nutritional factors influencing concentrations of milk urea nitrogen. Journal of Dairy Science, v. 80, p.2964-2971, 1997.

CHEN, X.B.; GOMES, M.J. Estimation of microbial protein supply to sheep and cattle based on urinary excretion of purine derivatives - an overview of technical details. Bucksburnd: Rowett Research Institute, International Feed Resources Unit, 1992. 21p. (Occasional publication)

CHEN, X.B.; MEJIA, A.T.; KYLE, D.J. et al. Evaluation of the use of the purine derivative: creatinine ratio in spot urine and plasma samples as an index of microbial protein supply in ruminants: studies in sheep. Journal of Agricultural Science, v.125, p.137-143, 1995.

CHIZZOTTI, M.L.; VALADARES FILHO, S.C.; VALADARES, R.F.D. et al. Excreção de creatinina em novilhos e novilhas. In: REUNIÃO ANUAL DA SOCIEDADE BRASILEIRA DE
ZOOTECNIA, 41., 2004, Campo Grande. Anais...Campo Grande: Sociedade Brasileira de Zootecnia, 2004. CD-ROM. Nutrição de ruminantes.

CLARK, J.H.; KLUSMEYER, T.H.; CAMERON, M.R. Microbial protein synthesis and flows of nitrogen fractions to the duodenum of dairy cows. Journal of Dairy Science, v.75, p.2304-2323, 1992.

COCHRAN, R.C.; ADAMS, D.C.; WALLACE, J.D. et al. Predicting digestibility diets with internal markers: Evaluation of four potential markers. Journal of Animal Science, v.63, p.14761483, 1986.

FUJIHARA, T.; ØRSKOV, E.R.; REEDS, P.J. et al. The effect of protein infusion on urinary excretion of purine derivatives in ruminants nourished by intragastric nutrition. Journal of Agricultural Science, v.109, p.7-12, 1987.

HARMEYER, J.; MARTENS, H. Aspects of urea metabolism with reference to the goat. Journal of Dairy Science, v.63, p.1707-1728, 1980 .

HOOVER, W.H.; STOKES, S.R. Balancing carbohydrates and proteins for optimum rumen microbial yield. Journal of Dairy Science, v.74, p.3630-3644, 1991.

LEÃO, M.I.; VALADARES FILHO, S.C.; RENNÓ, L.N. et al. Consumos e digestibilidades aparentes totais e parciais de matéria seca, matéria orgânica, proteína bruta e extrato etéreo em novilhos submetidos a três níveis de ingestão e duas metodologias de coleta de digestas abomasal e omasal. Revista Brasileira de Zootecnia, v.33, n.6, p.1604-1615, 2004.

LEÃO, M.I.; VALADARES FILHO, S.C.; RENNÓ, L.N. et al. Consumos e digestibilidades aparentes totais e parciais de carboidratos totais, fibra em detergente neutro e carboidratos não fibrosos em novilhos submetidos a três níveis de ingestão e duas metodologias de coleta de digestas abomasal e omasal. Revista Brasileira de Zootecnia, v.34, n.2, p.670-678, 2005.

NATIONAL RESEARCH COUNCIL - NRC. Nutrient requirements of beef cattle. 7.ed. Washington, D.C.: National Academy Press, 1996. 242p.

NATIONAL RESEARCH COUNCIL - NRC. Nutrient requeriments of dairy cattle. 7. ed. Washinton, D.C: National Academic Press, 2001. 381p.

NATIONAL RESEARCH COUNCIL - NRC. Predicting feed intake of food-producing animals. Washington, D.C.: National Academy Press, 1987. 96p.

NATIONAL RESEARCH COUNCIL - NRC. Ruminant nitrogen usage. Washington, D.C.: National Academy Press, 1985. 183p.

ORELLANA BOERO, P.; BALCELLS, J.; MARTÍN-ORÚE, S.M. et al. Excretion of purine derivates in cows: endogenous contribution and recovery of exogenous purine bases. Livestock Production Science, v.68, p.243-250, 2001.

PRESTON, R.L.; SCHNAKENBERG, D.D.; PFANDER, W.H. Protein utilization in ruminants. I. Blood urea nitrogen as affected by protein intake. Journal of Nutrition, v. 68 , p.281-288, 1965 .

RENNÓ, L.N. Consumo, digestibilidade total e parcial, produção microbiana, parâmetros ruminais e excreções de uréia e creatinina em novilhos alimentados com dietas contendo quatro níveis de uréia ou dois de proteína. Viçosa, MG: Universidade Federal de Viçosa, 2003. 252p. Tese (Doutorado em Zootecnia) - Universidade Federal de Viçosa, 2003.

RENNÓ, L.N.; VALADARES FILHO, S.C.; VALADARES, R.F.D. et al. Níveis de proteína na ração de novilhos de quatro grupos genéticos: estimativa da produção de proteína microbiana por intermédio dos derivados de purinas na urina. In: REUNIÃO ANUAL DA SOCIEDADE BRASILEIRA DE ZOOTECNIA, 40. 2003, Santa Maria. Anais...Santa Maria: Sociedade Brasileira de Zootecnia, 2003. CD-ROM. Nutrição de ruminantes.

RENNÓ, L.N.; VALADARES, R.F.D.; LEÃO, M.I. et al. Estimativa da produção de proteína microbiana pelos derivados de purinas na urina em novilhos. Revista Brasileira de Zootecnia, v.29, p.1223-1234, 2000 . 
SILVA, D.J., QUEIROZ, A.C. Análise de alimentos (métodos químicos e biológicos). 3.ed. Viçosa, MG: Universidade Federal de Viçosa, 2002. 235p.

UNIVERSIDADE FEDERAL DE VIÇOSA - UFV. SAEG - Sistema de análises estatísticas e genéticas. Versão 8.0. Viçosa, MG: 1998. 150p.

VAGNONI, D.B.; BRODERICK, G.A.; CLAYTON, M.K. et al. Excretion of purine derivatives by holstein cows abomasally infused with incremental amounts of purines. Journal of Dairy Science, v.80, p.1695-1702, 1997.

VALADARES, R.F.D.; BRODERICK, G.A.; VALADARES FILHO, S. C. et al. Effect of replacing alfafa silage with high moisture corn on ruminal protein synthesis estimated from excretion of total purine derivatives. Journal of Dairy Science, v. 82, p.2686-2696, 1999.

VALADARES, R.F.D.; GONÇALVES, L.C.; RODRIGUEZ, N.M. et al. Níveis de proteína em dietas de bovinos. 4. Concentrações de amônia ruminal e uréia plasmática e excreções de uréia e creatinina. Revista Brasileira de Zootecnia, v.26, p.1270-1278, 1997.

Van SOEST, P.J. Nutritional ecology of the ruminant. 2. ed. London: Constock Publishing Associates, USA, 1994. 476p.

VERBIC, J.; CHEN, X.B.; MACLEOD, N.A. et al. Excretion of purine derivatives by ruminants. Effect of microbial nucleic acid infusion on purine derivative excretion by steers. Journal of Agricultural Science, v.114, p.243-248, 1990.
VIEIRA, P.F. Efeito do formaldeído na proteção de proteínas e lipídios em rações para ruminantes. Viçosa, $M G$ : Universidade Federal de Viçosa, 1980. 98p. Tese (Doutorado em Zootecnia) - Universidade Federal de Viçosa, 1980.

WEISS, W.P. Energy prediction equations for ruminant feeds. In: CORNELL NUTRITION CONFERENCE FOR FEED MANUFACTURERS, 61., 1999, Ithaca. Proceedings... Ithaca: Cornell University, 1999. p.176-185. 